\title{
Pattern of Drugs and Therapeutic Agents Exposure among Pediatric Inpatients in the Fatima University Medical Center
}

\author{
Subedi $\mathbf{N}^{1^{*}}$, Shrestha $\mathrm{B}^{2}$, Poudel $\mathbf{S}^{1}$, Bhattarai $\mathbf{A}^{1}$, Namrata $\mathrm{KC}^{1}$ \\ ${ }^{1}$ Lecturer, ${ }^{2}$ Associate Professor, Department of Pediatrics, \\ Gandaki Medical College \& Teaching Hospital, Pokhara, Nepal
}

\author{
Keywords \\ Drugs and therapeutic agents, Exposure, \\ Pediatric inpatient. \\ Corresponding author \\ *Dr. Nabraj Subedi \\ Lecturer, Department of Pediatrics \\ Gandaki Medical college and Teaching \\ Hospital, Pokhara, Nepal \\ Email: nrsped@gmail.com
}

\begin{abstract}
Background: Drugs and therapeutic agents exposure is essentially universal for persons, young and old in the Philippines. In the hospital, many drugs and therapeutic agents are being given to the patients according to severity of the illness. The evidence has suggested that complex medication combination increase the risk for adverse drug events. The most common results of many drugs and therapeutic agents are increased adverse drug reactions, drug-drug interactions and higher costs.
\end{abstract}

Objectives: To assess the prevalence and patterns of exposure to drugs and therapeutic agents among pediatric inpatients.

Methods: Study Design: Retrospective study. Setting: Pediatric inpatients in the Fatima University Medical Center. Patients: A total of 1075 patients younger than 19 years, excluding healthy newborn, hospitalized in 2011, representing a part of pediatric inpatients in the Philippines.

Results: The most common exposure was with D5.3NaCl, paracetamol, cefuroxime, salbutamol, zinc sulphate. Most of the pediatric inpatients received five or less number of medication varied by age and length of stay in the hospital. Pediatric inpatients were exposed to numerous drugs and therapeutic agents, especially patients with dengue III.

Conclusions: A large portion of pediatric inpatients are exposed to numerous drugs and therapeutic agents, especially patients with Dengue III.

\section{INTRODUCTION}

Drugs and therapeutic agents exposure is essentially universal for persons young and old in the Philippines. In the hospital, many drugs and therapeutic agents are being given to the patients in order to cure certain diseases. The number of therapeutic agents being administered to the patients varies according to severity of the illness. Polypharmacy is the use of multiple drugs by a patient, when too many drugs are prescribed than is clinically warranted, or even when all prescribed medications are clinically indicated but there are too many drugs to take ${ }^{1}$.
The evidence has suggested that complex medication combination increase the risk for adverse drug events. Exposure to many drugs and therapeutic agents is most common in the elderly but is also widespread in the general population ${ }^{2}$.

Drugs and therapeutic agents exposure is more prevalent in patients who changes doctors frequently to treat a particular illness and those who are buying over-thecounter medications on their own. The most common results of many drugs and therapeutic agents are increased adverse drug reactions, drug-drug interactions and higher costs. 
A large proportion of hospitalized children are exposed to numerous medications on a daily basis, according to a new study by Chris Feudtner (2012). In addition, children with rare conditions are more likely to be exposed to more drugs and therapeutic agents ${ }^{3}$.

In a developing country like the Philippines, many children are being hospitalized, and being exposed to multiple drugs and therapeutic agents every day.

To address these objectives, we used data from Fatima University Medical Center. The data set represent part of pediatric inpatients hospitalization in the Philippines. In this report we examine patterns of use of drugs and therapeutic agents among hospitalized pediatric patient (Excluding the healthy newborns) focusing on exposure to drugs and therapeutic agents, which has shown to be associated with an increase risk of adverse drug reaction in adult patients ${ }^{4,5}$.

\section{METHODS}

The data was collected from Fatima University Medical Center, Valenzuela city, Philippines. For this study, one year (2011) data were collected from the record section. We went through the chart and discharge summary of all inpatients from January 2011 to December 2011.

There was implementation of standardized drugs and therapeutic agent dictionary built up that were specified by 93 distinct codes and non specific drugs were narrowed to 1 code categories, using the FUMC Hospital Formulary (2011 Ed), the generic entities were grouped to major 15 categories ${ }^{6}$.

To describe the pattern of exposures, we calculated percentage of exposure to specific generic drugs and therapeutic agents by patient, by length of hospital stay. The number of exposures to discrete generic drugs and therapeutic agents were divided into three groups. The mean length of stay (LOS) was 4.07 (SD1.755). The mean age of the patient was 5.67 (SD 5.02). The total number of pediatric inpatients was 1075 . To assess the relationship of total drugs and therapeutic agents exposure by age and LOS, we categorized it into three groups and two groups respectively.

\section{RESULTS}

In the year 2011 sample, a total of 3329 pediatric patients younger than 19 years, 1075 experienced hospitalizations in Fatima University medical center (FUMC) ${ }^{7}$. Among the hospitalized patients 537 (50\%) were boys and 538 (50\%) were girls (Table 1).

Table1: Characteristics of patients in FUMC

\begin{tabular}{lccc}
\hline \multicolumn{2}{c}{ Patients } & Number & Percent \\
\hline Gender & Males & 537 & $50.0 \%$ \\
& Females & 538 & $50.0 \%$ \\
Age group & $<1 \mathrm{yr}$ & 170 & $15.81 \%$ \\
& $1-9 \mathrm{yr}$ & 642 & $59.72 \%$ \\
& $10-19 \mathrm{yr}$ & 263 & $24.46 \%$ \\
\hline
\end{tabular}

The pediatric patients are from one day to 18 year and 364 days $^{8}$. There were 170 patients under one year old, 642 patients under one to less than 10 years old and 263 patients under 10 to 19 year old as shown in Table 1.

Table 2 lists of 20 common generic medications exposure (excluding intravenous fluilds) in the FUMC reveals the prevalence of exposures to acetaminophen, salbutamol, ranitidine, diphenhydramine, cefuroxime, ampicillin, zinc sulphate. A complete list of number and percentage of patients hospitalized exposed to all drugs and therapeutic agent is available from the author.

Table 2: Top 35 drugs entity exposures by patients

\begin{tabular}{lc}
\hline \multicolumn{1}{c}{ Drugs entity } & \% of patients \\
\hline Paracetamol & $67.0 \%$ \\
Ibuprofen & $3.0 \%$ \\
Salbutamol & $21.7 \%$ \\
Ipratropium bromide & $8.4 \%$ \\
Budesonide & $6.0 \%$ \\
Ampicillin & $14.3 \%$ \\
Amikacin & $7.0 \%$ \\
Erythromycin & $1.3 \%$ \\
Gentamycin & $2.3 \%$ \\
Co-amoxiclav & $3.7 \%$ \\
Cefuroxime & $22.3 \%$ \\
Cefixime & $1.2 \%$ \\
Ceftriaxone & $6.3 \%$ \\
Clarithromycin & $5.1 \%$ \\
Cotrimoxazole & $1.1 \%$ \\
Metronidazole & $4.7 \%$ \\
Meropenem & $0.1 \%$
\end{tabular}




\begin{tabular}{lc}
\hline \multicolumn{1}{c}{ Drugs entity } & \% of patients \\
\hline Chloramphenicol & $0.2 \%$ \\
Anti Kochs & $1.0 \%$ \\
Cloxacillin & $0.8 \%$ \\
Other Antibiotics & $3.8 \%$ \\
Ointment & $4.9 \%$ \\
Vitamin C & $3.7 \%$ \\
Zinc & $16.2 \%$ \\
OMX & $5.4 \%$ \\
Bacillus Clausi & $7.7 \%$ \\
Hydrocortisone & $2.5 \%$ \\
N-acetylcysteine & $1.4 \%$ \\
Ranitidine & $6.0 \%$ \\
Famotidine & $3.7 \%$ \\
Diphenhydramine & $7.4 \%$ \\
Hydroxizine & $7.2 \%$ \\
Other Drugs & $5.3 \%$ \\
Diazepam & $4.0 \%$ \\
Phenobarbital & $1.2 \%$ \\
\hline
\end{tabular}

The pediatric patients were all selected from the general pediatric ward. The common intravenous fluid given to the patient during the length of hospital stay were as follows; 0.9\% normal saline (PNSS) (18.2\%), Ringer's lactate solution (PLR) (28.5\%), 5\% dextrose with $0.3 \%$ normal saline (D5 $0.3 \mathrm{NaCl})(50.9 \%)$ as tabulated in Table 3.

Table 3: Intravenous fluid exposure by Patients

\begin{tabular}{lc}
\hline \multicolumn{1}{c}{ Intravenous Fluids } & \% of patients \\
\hline PNSS & $18.2 \%$ \\
PLR & $28.5 \%$ \\
D50.3 NaCl & $50.9 \%$ \\
D5LR & $15.3 \%$ \\
D5IMB & $7.8 \%$ \\
D5NM & $1.0 \%$ \\
Voluven & $1.0 \%$ \\
Fresh frozen plasma & $0.6 \%$ \\
Packed RBC & $0.3 \%$ \\
Cryoprecipitate & $0.2 \%$
\end{tabular}

As illustrated in Figure 1, on the total length of stay in the hospital, $81.1 \%, 17.9 \%$ and $1.0 \%$ of patients received less than six, 6 to 10 and more than 10 drugs and therapeutic agents respectively.
Fig 1: Percentage of patients exposed to numbers drugs and therapeutic agents

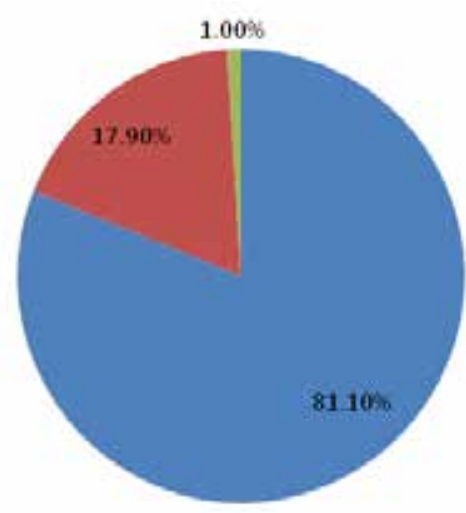

aless than 6

$=6$ to 10

m more than 10

The total number of drugs and therapeutic agents exposure was found ranging from one to 22. Twenty patients received only one medication and one patient received 22 medications. Most of the patients received three to six medications. As shown on figure 2, total number of medication given to the patients showed that three drugs and medications were given to $24.9 \%$ of patients, four and six were given to $23.4 \%$ and $18.0 \%$ of patients respectively.

Fig 2: Number of medication with respect to patients

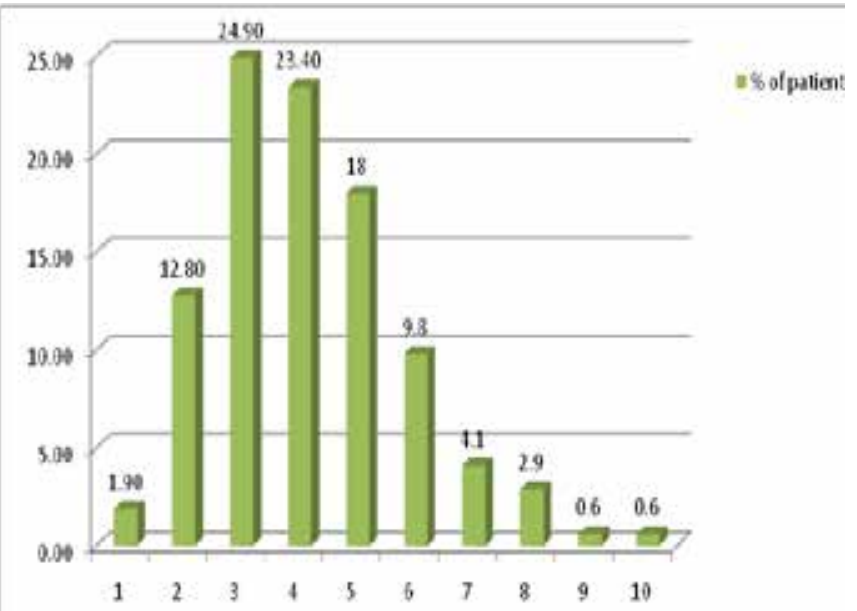

The pediatric patients hospitalized in the FUMC were staying in the hospital ranging from one to 16 days with the mean length of stay (LOS) 4.07 days. The LOS was divided into two groups: One staying for less than five days and another staying for five and more days. On comparing the LOS with the number of drugs and therapeutic agents exposure, it was found that $86.1 \%$ of patients were given less than six medications within less than five days (LOS). $2.7 \%$ of patients were given more than 10 medications in more than 5 days (LOS) (Table 4). 
Table 4: Number of medications given with respect to length of stay

\begin{tabular}{|c|c|c|c|c|c|c|}
\hline \multicolumn{7}{|c|}{ Total Medication } \\
\hline \multirow{2}{*}{$\begin{array}{l}\text { Length } \\
\text { of stay }\end{array}$} & \multicolumn{2}{|c|}{ Less than 6} & \multicolumn{2}{|c|}{6 to 10} & \multicolumn{2}{|c|}{ More than 10} \\
\hline & $\begin{array}{c}\text { Num- } \\
\text { ber }\end{array}$ & $\begin{array}{l}\text { Percent- } \\
\text { age* }\end{array}$ & $\begin{array}{c}\text { Num- } \\
\text { ber }\end{array}$ & $\begin{array}{c}\text { Percent- } \\
\text { age* }^{*}\end{array}$ & $\begin{array}{c}\text { Num- } \\
\text { ber }\end{array}$ & $\begin{array}{l}\text { Percent- } \\
\text { age* }\end{array}$ \\
\hline $\begin{array}{l}\text { Less } \\
\text { than } 5 \\
\text { days }\end{array}$ & 636 & $86.1 \%$ & 101 & $13.7 \%$ & 2 & $0.3 \%$ \\
\hline $\begin{array}{l}5 \text { days } \\
\text { and } \\
\text { above }\end{array}$ & 236 & $70.2 \%$ & 91 & $27.1 \%$ & 9 & $2.7 \%$ \\
\hline
\end{tabular}

$\left\{{ }^{*}\right.$ number of patients in percentage $\}$

The age of the pediatric patients were grouped into three categories: less than one year, one to less than 10 year and 10 to less than 19 year. As illustrated in Table 5 , for all age groups most of medications were less than six. In infants, $14.7 \%$ received 6 to 10 medications. For patients 10 years and above $1.9 \%$ of patients were exposed to more than 10 medications.

Table 5: Percentage of patients exposed to drugs and therapeutic agents by age group

\begin{tabular}{|c|c|c|c|c|c|c|}
\hline \multicolumn{7}{|c|}{ Total drugs and therapeutic agents } \\
\hline \multirow{2}{*}{$\begin{array}{l}\text { Age in } \\
\text { years }\end{array}$} & \multicolumn{2}{|c|}{ Less than 6} & \multicolumn{2}{|c|}{6 to 10} & \multicolumn{2}{|c|}{ More than 10} \\
\hline & $\begin{array}{c}\text { Num- } \\
\text { ber }\end{array}$ & $\begin{array}{l}\text { Percent- } \\
\text { age }\end{array}$ & $\begin{array}{c}\text { Num- } \\
\text { ber }\end{array}$ & $\begin{array}{l}\text { Percent- } \\
\text { age }\end{array}$ & $\begin{array}{c}\text { Num- } \\
\text { ber }\end{array}$ & $\begin{array}{c}\text { Percent- } \\
\text { age }\end{array}$ \\
\hline $\begin{array}{l}\text { Less than } \\
\text { one year }\end{array}$ & 144 & $84.7 \%$ & 25 & $14.7 \%$ & 1 & $0.6 \%$ \\
\hline $\begin{array}{l}\text { One to } \\
\text { less than } \\
10\end{array}$ & 501 & $78.0 \%$ & 136 & $21.2 \%$ & 5 & $0.8 \%$ \\
\hline $\begin{array}{l}10 \text { to less } \\
\text { than } 19\end{array}$ & 227 & $86.3 \%$ & 31 & $11.8 \%$ & 6 & $1.9 \%$ \\
\hline
\end{tabular}

The study was also done for few common diseases like dengue, pneumonia and acute gastroenteritis in relation to drugs exposure which revealed less medication were exposed to common condition. Level of exposure to drugs and therapeutic agents were higher for patients with cardiac diseases, and dengue III. Some of the common medical conditions were illustrated in the Table 6.
Table 6: Level of exposure to drugs and therapeutic agent for patient medical condition

\begin{tabular}{|c|c|c|c|c|c|c|}
\hline \multicolumn{7}{|c|}{ Total number of drugs and therapeutic agents } \\
\hline \multirow[t]{2}{*}{ Diagnosis } & \multicolumn{2}{|c|}{ Less than 6} & \multicolumn{2}{|c|}{6 to 10} & \multicolumn{2}{|c|}{ More than 10} \\
\hline & $\begin{array}{l}\text { Num- } \\
\text { ber }\end{array}$ & Percent & $\begin{array}{l}\text { Num- } \\
\text { ber }\end{array}$ & $\begin{array}{l}\text { Per- } \\
\text { cent }\end{array}$ & $\begin{array}{l}\text { Num- } \\
\text { ber }\end{array}$ & $\begin{array}{l}\text { Per- } \\
\text { cent }\end{array}$ \\
\hline DFS & 82 & $93.2 \%$ & 6 & $6.8 \%$ & 0 & $0 \%$ \\
\hline DHF I & 94 & $90.4 \%$ & 10 & $9.6 \%$ & 0 & $0 \%$ \\
\hline DHF II & 88 & $86.3 \%$ & 14 & $13.7 \%$ & 0 & $0 \%$ \\
\hline DHF III & 10 & $40.0 \%$ & 11 & $44.0 \%$ & 4 & $16.0 \%$ \\
\hline Pneumonia & 133 & $70.0 \%$ & 56 & $29.5 \%$ & 1 & $5 \%$ \\
\hline Gastroenteritis & 152 & $82.6 \%$ & 32 & $17.4 \%$ & 0 & $0 \%$ \\
\hline Tonsillitis & 48 & $90.6 \%$ & 5 & $9.4 \%$ & 0 & $0 \%$ \\
\hline $\begin{array}{l}\text { Systemic viral } \\
\text { infections }\end{array}$ & 16 & $100.0 \%$ & 0 & $.0 \%$ & 0 & $0 \%$ \\
\hline Febrile convulsion & 36 & $83.7 \%$ & 7 & $16.3 \%$ & 0 & $0 \%$ \\
\hline Neonatal sepsis & 33 & $91.7 \%$ & 3 & $8.3 \%$ & 0 & $0 \%$ \\
\hline 0ther diseases & 180 & $76.9 \%$ & 48 & $20.5 \%$ & 6 & $2.6 \%$ \\
\hline
\end{tabular}

\section{DISCUSSION}

The most common generic drugs and therapeutic agents to which children were exposed included intravenous fluids; analgesics such as paracetamol; anti-infective agents such as cefuroxime, ampicillin and amikacin; gastrointestinal drugs such as ranitidine, famotidine, diphenhydramine, zinc sulphate; certain classes of drugs, such as cardiovascular drugs and central nervous system drugs were less commonly used. In this study, $\mathrm{D} 5.3 \mathrm{NaCl}(50.9 \%)$ was found to be most commonly used intravenous fluid.

We also found that large proportion of hospitalized children were exposed to five or less drugs and therapeutic agents during entire days of their hospitalization with the most patients stayed in the hospital for less than five days.

The number of medication exposures for the admission of three common disease were also found less than six medications with $(\mathrm{LOS}<5)$, with slight increase of number of medication with increase in length of stay in case of 
pneumonia and dengue III.

This study based on data from 1075 admissions in 2011, the most common drug exposure were to paracetamol (67.0\%), salbutamol (21.7\%), cefuroxime (22.3\%), ampicillin (14.3\%), zinc sulfate (16.2\%), and noted in variation in the likely hood of exposure to medication based on patients age and diagnosis (Statistical testing for variation was not performed).

European study of outpatient pediatric drug use documented prevalent exposures to anti-infective agents (such as amoxicillin, amoxicillin/clavulanic acid, clarithromycin, or azithromycin, with $48 \%$ of the population exposed to an anti-infective agent during the course of a year) dermatologic drugs (such as fusidic acid, hydrocortisone, or miconazole, with $30 \%$ annual exposure); and respiratory drugs (such as albuterol, fluticasone, or desloratadine, with 30\% annual exposure). This study also found substantial variation in likelihood of exposure by patient age and sex (especially for adolescent girls) ${ }^{9}$.

An American study of in-patient found that the most common generic drugs and therapeutic agents to which children were exposed included intravenous fluids; analgesics such as the narcotics fentanyl and morphine or the antipyretics/analgesics acetaminophen and ibuprofen; anti-infective agents such as ampicillin, gentamicin, and cephalosporins; anesthetic agents such as lidocaine and propofol; gastrointestinal drugs such as ranitidine, ondansetron, and metoclopramide; and a bundle of drugs often provided to newborns as part of routine care, including vitamin $\mathrm{K}$, erythromycin eye drops, immunization drugs, and application of triple dye anti-infective agents to the umbilicus ${ }^{3}$.

An analysis of medication use in children with autism reveals polypharmacy is common, with up to $20 \%$ of children between the ages of three and 12 years being prescribed four or more medications. The most commonly used drugs were stimulants and antidepressants, followed by antipsychotics and other psychotropics ${ }^{10}$.

While the present study has considerable pediatric inpatient drug and therapeutic agent exposures, five limitations of the study warrant consideration. First, the study was limited to inpatient only (excluding pediatric inpatient hospitalized for surgical, ophthalmological, or ENT problems), and is also for outpatient drugs exposure studies. Second, the drugs mentioned on the medication sheet includes the medication prescribed as PRN which does not necessarily assure that the patient received the medication, or the patient may have refused the medication, or has been change in the course of therapy from what was prescribed.

Third, we do not report drug doses in terms of either the amount of medications or the number of doses. Fourth, the data do not contain complete information on the indication and purpose for which the medication is prescribed. This is an inherent limitation regarding the certainty with which investigator can study drugs used for particular purpose. Fifth, drug classification schemes, which tends to categorize drugs according to FUMC Hospital formulary. A drug that was not included in the formulary were categorized as others and same drugs can be placed in two categories.

\section{CONCLUSIONS}

Pediatric inpatients were exposed to numerous drugs and therapeutic agents, especially patients with dengue III, and cardiac problems. Most of the pediatric inpatients received five or less number of drugs and medication by age and length of stay in the hospital. The most common exposure to drugs and therapeutic were with $\mathrm{D} 50.3 \mathrm{NaCl}$, paracetamol, cefuroxime, salbutamol, zinc sulphate. The number of exposure to different drug and therapeutic agent was 1 (lowest) and 22 (highest).

The finding and the data of this study offers important means to improve pediatric inpatient medication efficacy, effectiveness and safety. Ranking of drug and therapeutic agents based on the prevalence of hospitalized children's exposure can guide prioritization for further research. For example, research should focus on drugs that used principally for off-label of indications. Researcher should also develop methods to detect adverse event for pediatric patients $^{11}$.

Second, the level of drugs and therapeutic agents exposure found in this study raises patient safety concerns on pediatric patient, as adverse drug events that has been documented for adults in both hospital and nursing home settings ${ }^{11,12}$.

For pediatric patients at PICU and NICU who are likely to be exposed to numerous drugs and therapeutic agents, observational study of treatment to detect adverse event and health outcome is recommended. The study encourages other researchers to conduct similar study in large scale, including hospital from rural and urban area. 


\section{REFERENCES}

1. Polypharmacy in the elderly: A literature review. J Am Acad Nurse Pract. 2005; 17: 12.

2. Haider SI, Johnell KW et al. The influence of educational level on polypharmacy and inappropriate drug use: A register-based study of more than 600,000 older people. Journal of the American Geriatrics Society. 2009; 57(1): 62-69.

3. Chris Feudtner, Dingwei dai et al. Prevalence of polypharmacy exposure among hospitalized children in the United States. Arch Pediatr Adolese Med. 2012; 166(1): 9-16.

4. Nguyen JK, Fouts MM, Kotabe SE, Lo E. Polypharmacy as a risk factor for adverse drug reactions in geriatric nursing home residents. Am J Geriatr Pharmacother. 2006; 4(1): 36-41.

5. Joshua L, Devi P, Guido S. Adverse drug reactions in medical intensive care unit of a Tertiary Care Hospital.
Pharmacoepidemiol Drug Saf. 2009; 18(7): 639-64).

6. FUMC Hospital Formulary series II (2011).

7. Annual census of department of pediatric 2011.

8. Core Pediatric, Philippine Pediatric Society, 2009.

9. Sturkenboom MC, Verhamme KM, Nicolosi A, et al. TEDDY European Network of Excellence. Drug use in children: Cohort study in three European countries. BMJ. 2008; 337: a2245

10. Polypharmacy common among children with autism. IMFAR, 2009.

11. Takata GS, Mason W, et al. Development, testing, and findings of a pediatric-focused trigger tool to identify medication related harm in US children's hospitals. Pediatrics. 2008; 121(4): e927-e935.

12 Nguyen JK, Fouts MM, Kotabe SE, Lo E. Polypharmacy as a risk factor for adverse drug reactions in geriatric nursing home residents. Am J Geriatr Pharmacother. 2006; 4(1): 36-4. 